\title{
Bile acid-polyamine conjugates as synthetic ionophores
}

\author{
Deepak B. Salunke, Braja G. Hazra, and Vandana S. Pore* \\ Organic Chemistry Synthesis Division, National Chemical Laboratory, Pune 411 008, India \\ Email: hazra@ems.ncl.res.in,vspore@dalton.ncl.res.in \\ Dedicated to Professor (Mrs) Asima Chatterjee \\ (received 18 Nov 03; accepted 01 March 04; published on the web 12 March 04)
}

\begin{abstract}
Ion transport across membrane is crucial in living cells. Proteins that serve as ion channels or carriers provide this activity. The desire to understand these proteins, along with the need for new antibiotics, has spurred development of ion channel models. This short review describes the utilization of bile acid-polyamine conjugates as synthetic ionophores and extremely useful leads in the process of drug discovery. Relevant examples are included to illustrate the use of bile acidpolyamine conjugates as synthetic ionophores.
\end{abstract}

Keywords: Amphiphile, synthetic ionophore, cationic peptides, steroidal dimers, bile acid amides

\section{Contents}

Introduction

1. Design of ionophores as Amphotericin B mimics

2. Design of ionophores as Polymixin B mimics

3. Bile acid hybrids of chiral aminoalcohols

4. Design of ionophores as Squalamine mimics

5. Bile acid dimers as synthetic ionophores

Conclusions

\section{Introduction}

Due to emergence of drug-resistant strains of microorganisms there is significant need for a new class of antimicrobial agents to which bacteria or fungi would be unlikely to develop resistance. Drugs that function at membrane level are less likely to encounter resistance by microbes ${ }^{1}$ than 
drugs that operate at the cytoplasmic or nuclear level as in the former case cell death takes place without entering the cytoplasm of the microbe. The new class of membrane-disrupting drugs is ideal for this purpose. Many membrane active antimicrobial agents are known. ${ }^{2}$ These molecules generally have cationic residues along with hydrophobic aminoacids. In these compounds generally the cationic residues are clustered on one face of the molecule, while the hydrophobic part is on an opposite face. ${ }^{3}$ These molecules can therefore be schematically represented as shown in figure 1.

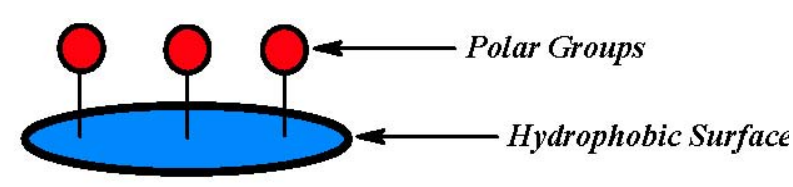

Figure 1. Schematic representation of Facial Amphiphiles.

Ionophores are the compounds that transport the ions across the phospholipid bilayers. Interest in the design and synthesis of such molecules has intensified in recent years. These molecules could find use in the development of novel ionophoric devices. ${ }^{4}$ The ultimate goal of this review is to discuss the recently designed pore forming amphiphiles/ionophores that can "punch" holes in the plasmamembrane of bacterial and fungal cells, but not in mammalian membranes. Such holes are expected to result in the rapid release of vital cellular constituents and ultimately in cell death.

\section{Design of ionophores as Amphotericin B mimics}

Amphotericin B (Amp B) $\mathbf{1}$ is a widely used antifungal drug for systemic fungal infections. ${ }^{5}$ It kills the cells by punching holes in the cell membranes. Drug resistance towards Amp B is extremely rare during its therapeutic use. ${ }^{6}$ However, due to its high toxicity and apparent inability to be metabolized, there was a need of biodegradable alternatives with higher membrane selectivity. Regen and coworkers sought the simplest molecules that are capable of forming ion channels and synthesized ${ }^{7}$ sterol-oligo conjugate 2 . The compound 2 obtained from 5 androstene-3в 17 в -diol exhibited significant ionophoric activity and is viable as a functional equivalent of Amp B.

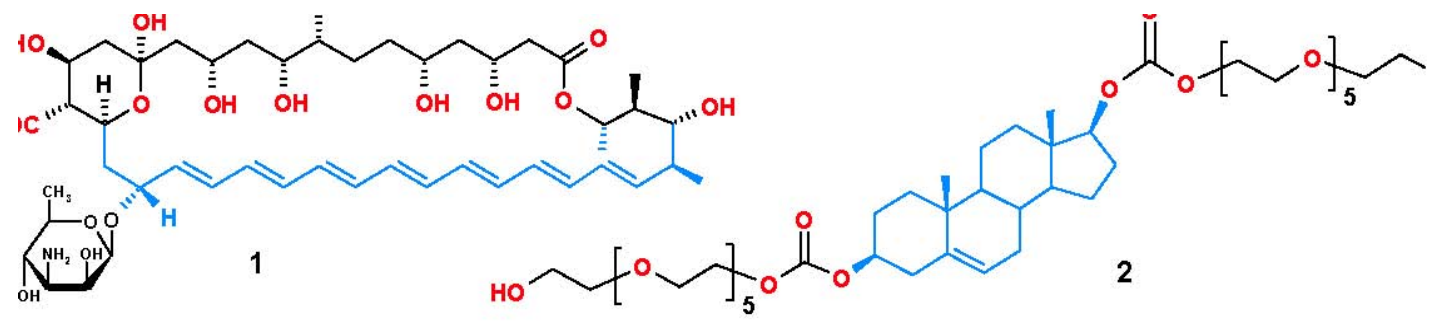




\section{Design of ionophores as Polymyxin B mimics}

Acquired resistance to membrane active compounds requires significant changes in the membrane structure to cause alterations in membrane permeability. ${ }^{8}$ Polymyxin B (PMB) 3 contains a lipophilic acyl chain and a heptapeptide ring that is responsible for lipopolysaccharide (LPS) binding. Resistance to PMB involves modification of LPS in the outer membranes of Gram negative bacteria. ${ }^{9}$ Since PMB is difficult to prepare and purify simple molecules capable of associating with LPS and alter the permeability of Gram- negative bacteria were designed. ${ }^{10}$

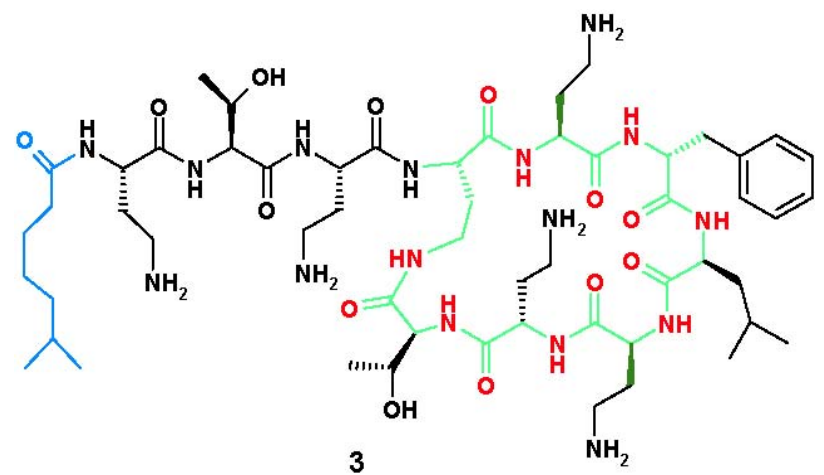

There are two major approaches in designing PMB mimics i) Design of cationic peptides containing cationic and hydrophobic amino acids ii) Modification of steroids with amino acids and/or polyamines. This review will provide a detailed description of the second approach.

Initial steroid based mimics of PMB were designed on simple modeling of PMB by using bile acids. ${ }^{11}$ In PMB the amine groups on the macro ring are oriented on one face of the molecule but are segregated from the hydrophobic groups. PMB mimics $\mathbf{4}$ to $\mathbf{6}$ have been synthesized from cholic acid. Bile acids have attracted significant attention due to availability and the orientation of the hydroxyl groups, that may be exploited in pedant-type receptors, ${ }^{12}$ linear dimeric hosts ${ }^{13}$ or facial amphiphiles. ${ }^{14}$ In addition, bile acids are natural ligands specifically recognized by hepatic cells and are amphiphilic molecules that undergo a biological recycling during enterohepatic circulation. ${ }^{15}$
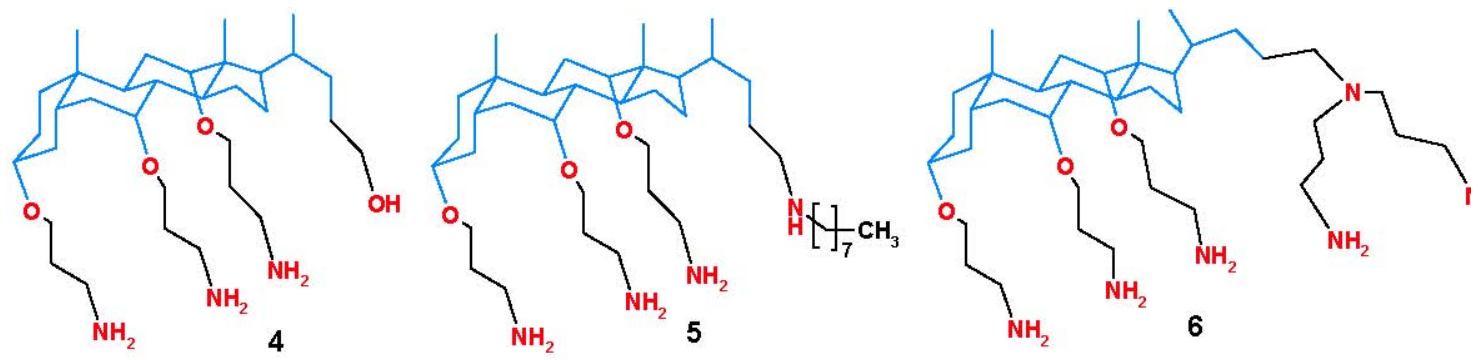
Amino groups have been separated from the hydrophobic steroid moiety by ether linkage with streochemically oriented oxygen atoms which force the amine groups to occupy one face of the steroid. This allows the cholic acid derivatives $\mathbf{4}$ to $\mathbf{6}$ to exhibit facial amphiphilicity common to cationic peptide antibiotics. Compound 5 shows potent bactericidal activity against Gramnegative and Gram-positive bacteria while compound 4 which has no hydrophobic chain at C-24 does not show bactericidal activity against Gram-negative bacteria. This parallels to that of PMB and its derivatives. ${ }^{16}$

As a potential means of increasing the cell selectivity of cationic steroid antibiotics, amino acids have been attached to steroid scaffolding. The rationale for using amino acids is that the amino group will provide the cationic recognition and the side chains may provide additional associative interactions with a specific binding target, thereby increasing the affinity and potentially the selectivity. Amino acids are incorporated on to cholic acid by ester ${ }^{17}$ or amide ${ }^{18}$ linkages to yield compounds $\mathbf{7}$ and $\mathbf{8}$.

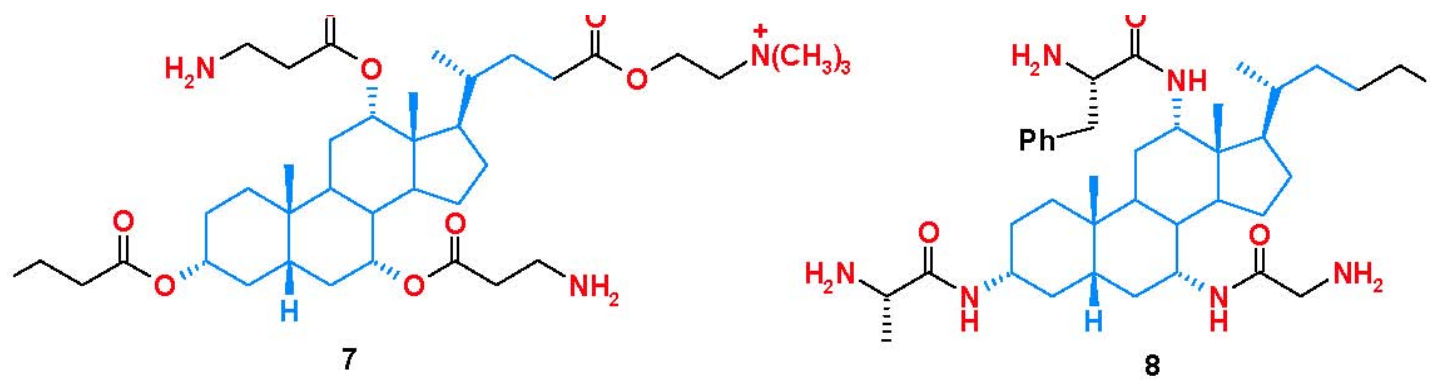

\section{Bile acid hybrids of chiral aminoalcohols}

By making use of the amphiphilic nature of bile acids and broad spectrum antibiotic activity of chloramphenicol 9 we have recently designed and synthesized ${ }^{19}$ eight new amides (18 to 25) derived from chiral amino alcohols (10 to 13) and bile acids such as cholic acid 14 and deoxycholic acid 15 (Scheme 1). Some of these easily accessible amides showed moderate antibacterial and antifungal activities. 


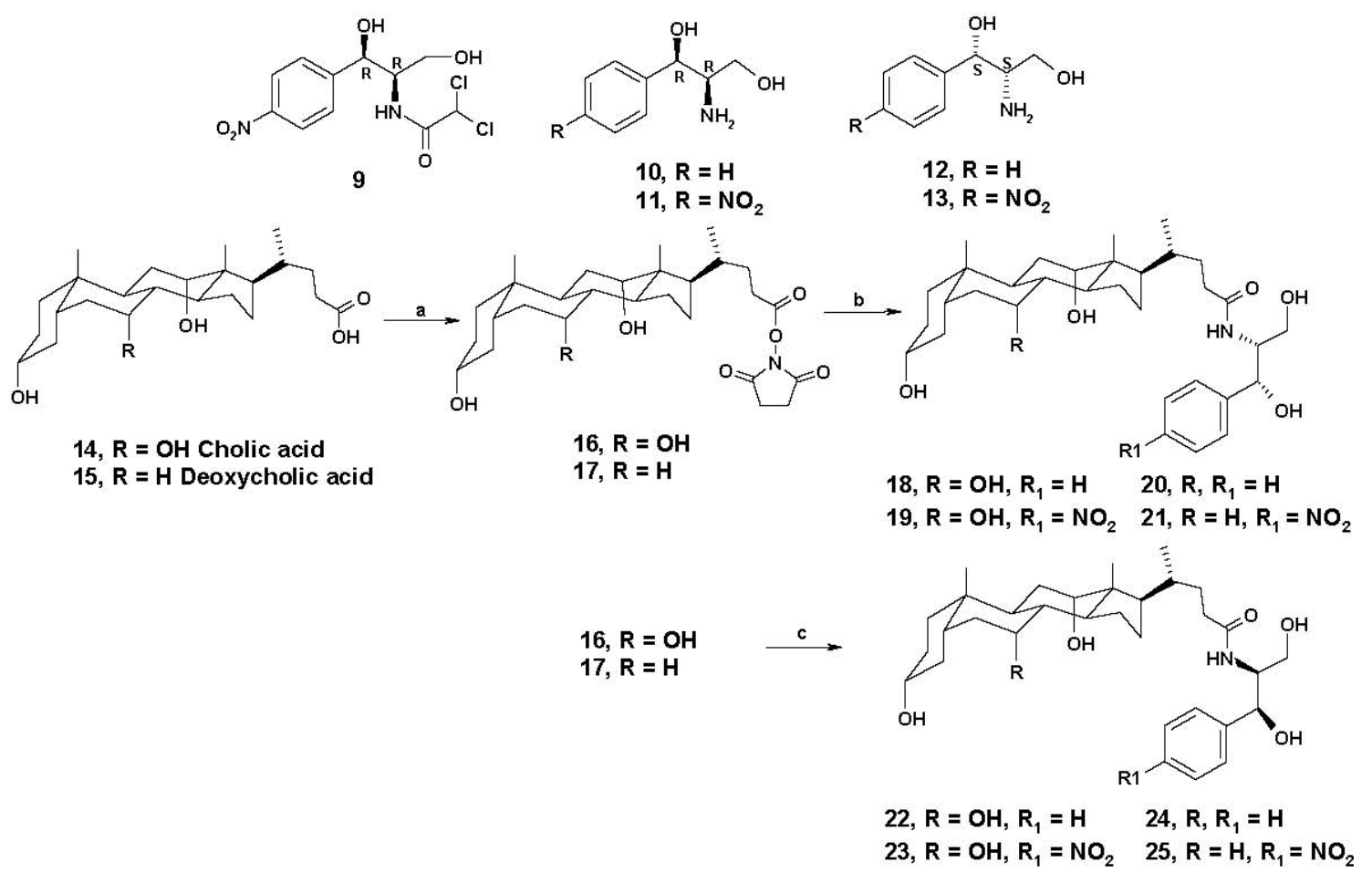

\section{Scheme 1}

Reagents and conditions: a) N- Hydroxy succinimide, DCC, THF- $\mathrm{CH}_{3} \mathrm{CN}, 25{ }^{0} \mathrm{C}, 18 \mathrm{~h},(\mathbf{1 6}, 83$ $\%$ yield; $1784 \%$ yield)); b) (1R, 2R)-1-phenyl-2-amino-1, 3-propanediol, DMF, $25{ }^{0} \mathrm{C}, 1.5 \mathrm{~h}$, (18, $92 \%$ yield, 20, $88 \%$ yield) or (1R, 2R)-1-para-nitrophenyl-2-amino-1, 3-propanediol, DMF, $25{ }^{0} \mathrm{C}, 1.5$ h, (19, $86 \%$ yield, 21, $81 \%$ yield); c) (1S, 2S)-1-phenyl-2-amino-1, 3propanediol, DMF, $25{ }^{\circ} \mathrm{C}, 1.5 \mathrm{~h},(22,90 \%$ yield, 24, $92 \%$ yield) or (1S, 2S)-1-para-nitrophenyl2-amino-1, 3-propanediol, DMF, $25{ }^{0} \mathrm{C}, 1.5 \mathrm{~h},(23,79 \%$ yield, 25, $82 \%$ yield).

Antibacterial activity data of compounds $\mathbf{1 8}$ to $\mathbf{2 5}$ showed that some of the newly synthesized amides are active against Gram-positive bacteria. Among them compound 25, synthesized from deoxycholic acid and amino alcohol 13 showed moderate antibacterial activity against most of the Gram-positive bacteria while compounds 18, 21, 22, 23 and 24 are active against some of the Gram-positive bacteria.

Antifungal activity data of compounds 18 to 25 showed that only compound 20, which was synthesized from deoxycholic acid and amino alcohol 10 was found to be active (IC-50, 62.5 $\mu \mathrm{g} / \mathrm{ml}$ ) against pathogenic fungus Cryptococcus neoformans. This might lead to the development of new drugs. 


\section{Design of ionophores as Squalamine mimics}

Squalamine 26 is a novel steroid-spermidine conjugate that has recently been isolated ${ }^{20}$ from tissues of the dogfish shark, Squalus acanthus. This unusual natural product shows antimicrobial activity against a broad spectrum of microorganisms. In common with Amp B 1 that consists basically of a lipophilic half and a polar half in a large ring, squalamine may be depicted in a similar cyclic form 27. This salt-bridged cyclic form consists of an upper lipophilic sterol part and lower part is hydrophilic polyamine chain. In this form squalamine could function as an

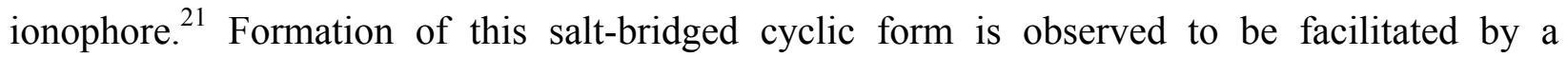
hydroxyl group at the $\mathrm{C}-7$ position during structure minimization in PCMODEL

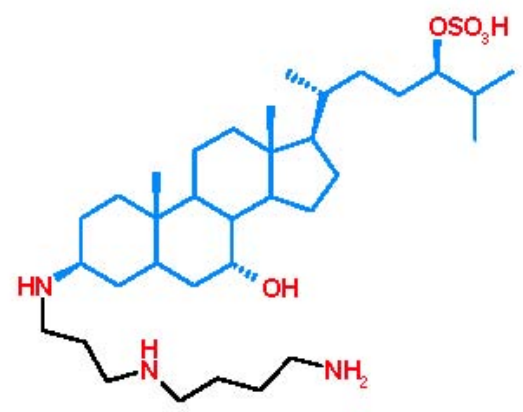

26

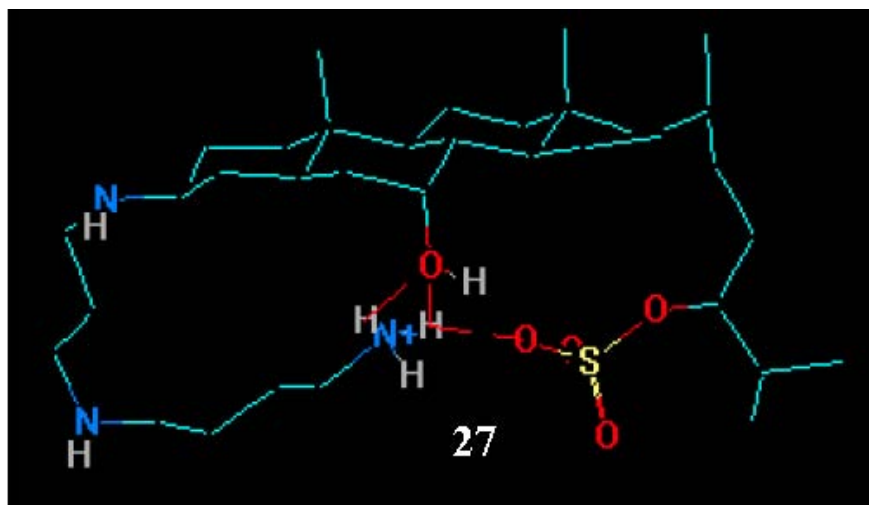

The minimum structural elements that are necessary to create the functional equivalent of squalamine mimic would consist of i) a rigid hydrophobic unit, ii) a flexible hydrophilic chain that is linked to hydrophobic unit, iii) a pendant polar head group. Based on this, mimics of squalamine have been prepared in which polyamines are attached to a variety of steroid molecules including cholic acid and deoxycholic acid.

Squalamine mimics 28 to $\mathbf{3 4}$ were designed and easily synthesized from bile acids by exchanging the positions occupied by the sulfate and polyamine groups. Many of these compounds displayed antibacterial activities comparable to those of squalamine. Among this squalamine mimic 28 demonstrated potent synergism with rifampin against many Gram-negative organisms. $^{22,23}$ 


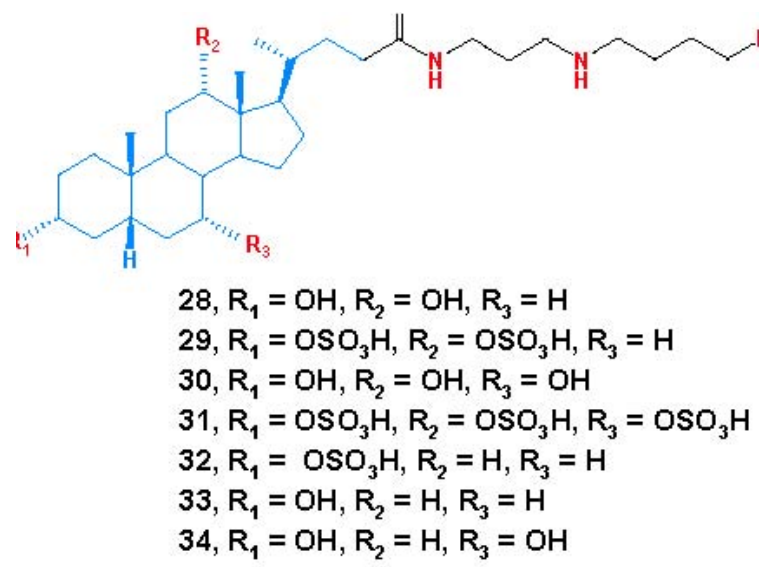

Squalamine mimics $\mathbf{3 5}$ to $\mathbf{3 8}$ functions as ionophores and exhibit membrane selectivity based on surface charge. ${ }^{24}$ Compound $\mathbf{3 6}$ functions, as an ionophore by discharging a $\mathrm{pH}$ difference across the vesicle membrane but compounds 35, 37 and $\mathbf{3 8}$ did not. A kinetic analysis of the ionophoric properties of $\mathbf{3 6}$ has implicated dimers as being responsible for ion transport. Compound 36 was found to be active for $\mathrm{H}^{+} / \mathrm{OH}^{-}$transport but not for $\mathrm{Na}^{+}$ion transport. ${ }^{24,} 25$ Compound 38 showed $^{26}$ exactly the opposite properties to that of compound 36 . It is active for $\mathrm{Na}^{+}$ion transport but not for $\mathrm{H}^{+} / \mathrm{OH}^{-}$transport. Very recently there are reports ${ }^{4,27,28}$ on the synthesis of ion conductors $\mathbf{3 9}$ to $\mathbf{4 2}$ derived from spermine and cholic acid with varying degrees of facial amphiphilicity. These compounds promote the passive transport of $\mathrm{Na}^{+}$across phosphotidylcholine vesicles however this transport activity decreases substantially as the thickness of the bilayer is increased. A dendritic approach to the construction of a homologous series of pore-forming amphiphiles has been reported, ${ }^{29}$ based on the use of spermidine, spermine, lysine, and cholic acid.

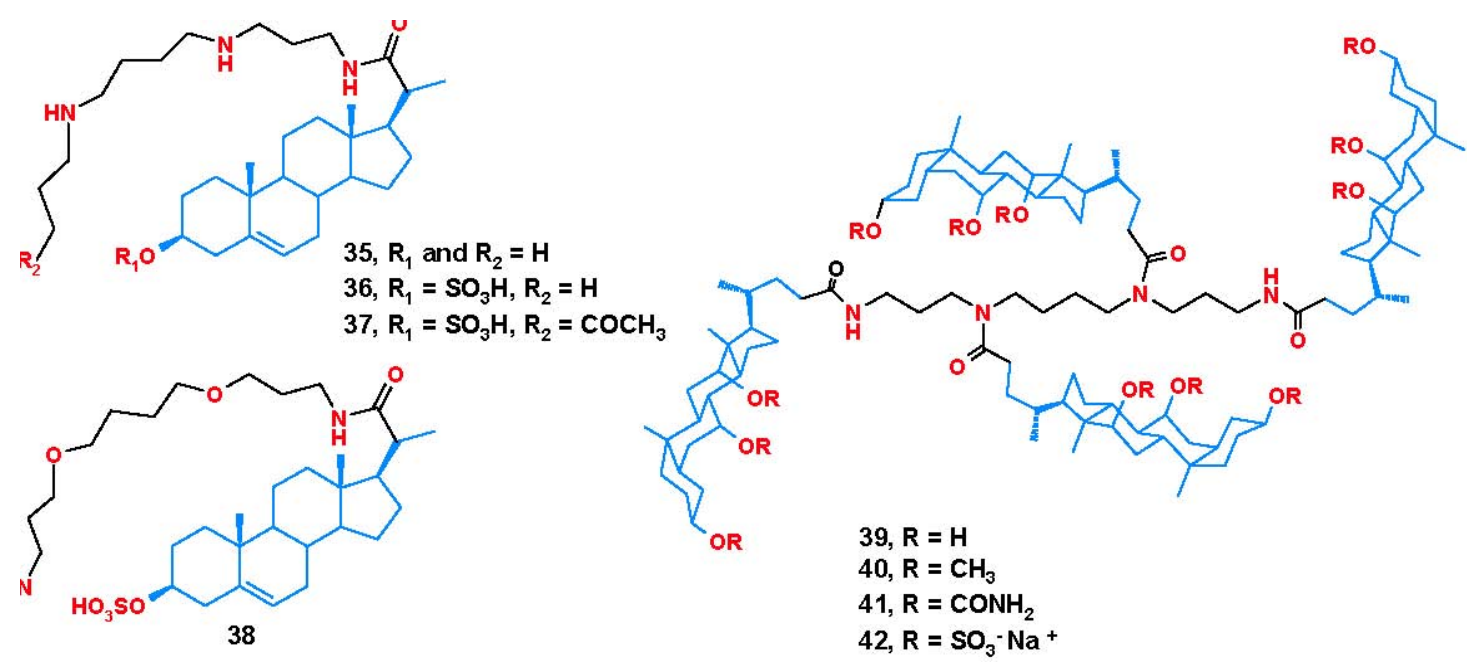




\section{Bile acid dimers as synthetic ionophores}

A common feature of bile acid derived antimicrobials is the potential to exhibit facially amphiphilic conformations. Facial amphiphiles are the compounds, which contain hydrophilic as well as hydrophobic surfaces. ${ }^{3}$ Polyene macrolide antibiotics like Amp B 1, peptide antimicrobial agents such as polymixin-B (PMB) $\mathbf{3}$ and sterol polyamine conjugate squalamine 26 can achieve such type of amphiphilicity. ${ }^{30,31}$ Although squalamine mimic 28 to 38 and PMB mimics $\mathbf{4}$ to $\mathbf{8}$ are morphologically dissimilar, they display similar activities. ${ }^{32}$

Based on these observations we thought of an amphiphile topology that has not previously received much attention in synthetic systems: partially rigid structure with three discrete faces, two of which are non-polar and one polar face sandwiched within non polar faces (figure 2).

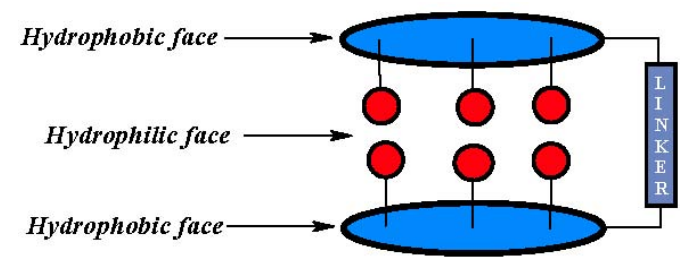

Figure 2. Schematic representation of novel facial amphiphile.

In this system, the steroid skeleton provides hydrophobic surface and hydroxyl groups can play a job of polar head group. Different linkers can be used so that additional hydrophobicity can be achieved. To support our hypothesis novel steroidal dimers $\mathbf{4 3}$ - 46 were synthesized (Scheme 2) and their antifungal activity was evaluated. ${ }^{33}$ Very recently clinical researchers in London reported exciting antitumor activity by the antifungal drug ${ }^{34,35}$ trichostatin A. Therefore we also examined antiproliferative activity of these newly synthesized steroidal dimers.
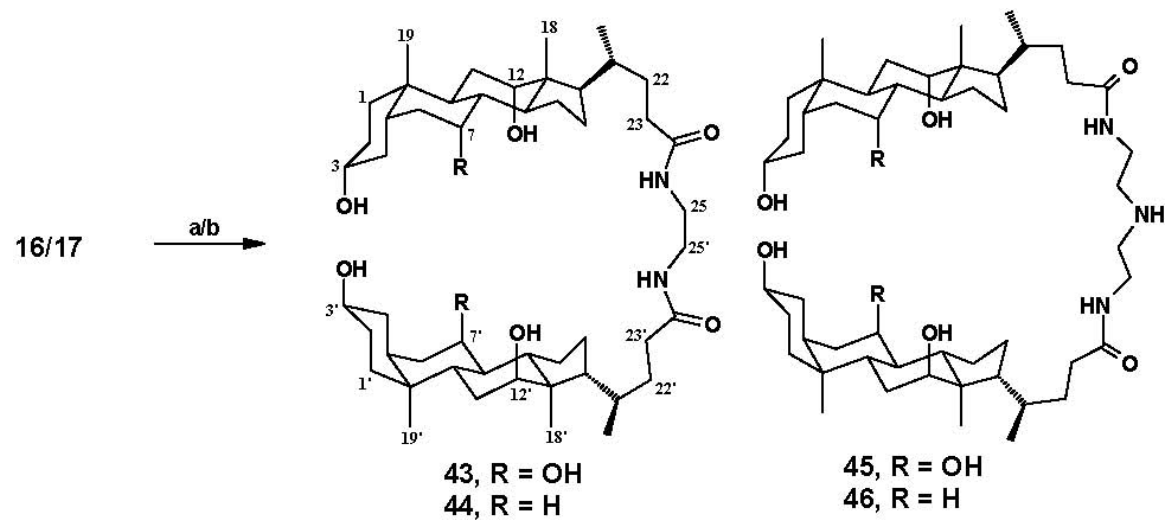

\section{Scheme 2}

Reagents and conditions: a) Ethylenediamine, DMF, $25{ }^{0} \mathrm{C}, 1.5 \mathrm{~h}$; (43, $96 \%$ yield; 44, $97 \%$ yield); b) Diethylenetriamine, DMF, $25{ }^{0} \mathrm{C}, 1.5 \mathrm{~h}$; (45, $95 \%$ yield; $46,98 \%$ yield). 
Compounds $\mathbf{4 3}$ to $\mathbf{4 6}$ were examined for antifungal activity against five different isolates of Candida albicans, a human pathogen and two non-pathogenic dimorphic fungi Benjaminiella poitrasii and Yarrowia lipolytica as model systems. Cycloheximide, a protein synthesis inhibitor was used as a standard inhibitor for comparison. The MIC for compound 45 is $11.32 \mathrm{nM}$ for all five C. albicans isolates, B. poitrassi and Y. lipolytica, the MIC values for the compound 46 ranged between 10-25 nM while compounds 43 and $\mathbf{4 4}$ did not show any zone of inhibition even upto $500 \mathrm{nM}$ concentration. However, in case of cycloheximide, the MIC value is much higher and ranged between $250-500 \mathrm{nM}$ for isolates of C. albicans. MIC of cycloheximide was $71 \mathrm{nM}$ in B. poitrasii and $106 \mathrm{nM}$ in Y. lipolytica.

The antiproliferative activity of all the four compounds was tested against human cancer cells; HEp-2 and MCF-7. The compounds 44 and 46 elicited a significant reduction in proliferation of both HEp-2 and MCF-7 cells. The compound 44 at $10 \mu \mathrm{M}$ concentration totally inhibited the growth of MCF-7 and HEp-2 cells. $\mathrm{IC}_{50}$ values for compound 44 on HEp-2 and MCF-7 cells were between 2-3 $\mu \mathrm{M}$.

The results suggested that compound $\mathbf{4 5}$ has potential as an antifungal agent when tested against both pathogenic and non-pathogenic fungi. Thus compound $\mathbf{4 5}$ may lead to a very good antifungal agent as it is selectively toxic to fungal cells at nanomolar concentration and does not have any profound effect on cell proliferation. On the other hand compound 44 which is not at all active against fungal cells exhibited good antiproliferative activity. The growth suppressive effect of compound $\mathbf{4 4}$ and $\mathbf{4 6}$ appears to be influenced by the length of side chain present. Since compound 43 and 45 had no effect on cell survival, the absence of hydroxyl group at C-7 position plays a critical role in toxicity of these compounds towards human cells. Thus extensive SAR studies should be carried out so that one can reach to the appropriate explanation for the presence or absence of a particular functionality in these dimers.

\section{Conclusions}

Due to emergence of drug resistance strains of microorganisms, there is a significant need for a new class of antimicrobial agents. Mimics of amphtericin B, polymixin B and squalamine derived from bile acid showing ionophoric activity may be probable candidates of this class as membrane active drugs. Studies regarding formation of channels by our compounds are under investigation.

\section{Acknowledgements}

One of the authors $(\mathrm{BGH})$ thanks the Department of Science and Technology, New Delhi, for financial support. 


\section{References}

1. Naka, K.; Sadownik, A.; Regen, S. L. J. Am. Chem. Soc. 1993, 115, 2278.

2. Hancock, R.; Falla, T.; Brown, M. Adv. Microb. Phys. 1995, 37, 135.

3. Stein, T. M.; Gellman, S. H. J. Am. Chem. Soc. 1992, 114, 3943.

4. Bandyopadhyay, P.; Janout, V.; Zhang, L.; Regen, S. L. J. Am. Chem. Soc. 2001, 123, 7691.

5. Lasic, D. D. Nature 1992, 355, 279.

6. (a) Finkelstein, A.; Holz, R. In Membranes 2: Lipid Bilayers and Antibiotics; Eisenman, G., Ed.; Marcel Dekker, Inc.: New York, 1973, Chapter 5. (b) Gale, E. F. In Macrolide Antibiotics: Chemistry, Biology and Practice; Omura, S., Ed.; Academic Press: New York, 1984; Chapter 11. (c) Hahn, F. E. Antibiotics Vol. 11, Mechanism of Action of Antieukaryotic and Antiviral Compounds; Springer-Verlag: New York, 1979.

7. Stadler, E.; Dedek, P.; Yamashita, K.; Regen, S. L. J. Am. Chem. Soc. 1994, 116, 6677.

8. Vaara, M.; Nurminen, M. Antimicrob. Agents Chemother. 1999, 43, 1495.

9. Vaara, M.; Vaara, T. Nature 1983, 303, 526.

10. Li, C.; Peters, A. S.; Meredith, E. L.; Allman, G. W.; Savage, P. B. J. Am. Chem Soc. 1998, 120, 2961.

11. Savage, P. B.; Li, C. Exp. Opin. Invest. Drugs 2000, 9, 263.

12. (a) Boyce, R.; Li, G.; Nestler, H. P.; Suenaga, T.; Still, W. C. J. Am. Chem Soc. 1994, 116, 7955. (b) Davis, A. P.; Perry, J. J.; Williams, R. P. J. Am. Chem Soc. 1997, 119, 1793.

13. (a) McKenna, J.; McKenna, J. M.; Thornthwaite, D. W. J. Chem. Soc., Chem. Commun. 1977, 809. (b) Janout, V.; Lanier, M.; Regen, S. L. J. Am. Chem. Soc. 1996, 118, 1573.

14. (a) Cheng, Y.; Ho, D. M.; Gottlieb, C. R.; Kahne, D.; Bruck, M. A. J. Am. Chem. Soc. 1992, 114, 7319. (b) Venkatasan, P.; Cheng, Y.; Kahne, D. J. Am. Chem. Soc. 1994, 116, 6955.

15. (a) Kramer, W.; Wess, G. Eur. J. Clin. Invest. 1996, 26, 715. (b) Lehmann, T.; Engels, J. Bioorg. Med. Chem. 2001, 9, 1827.

16. Schmidt, E. J.; Boswell, S. R.; Walsh, J. P.; Schellenberg, M. M.; Winter, T. W.; Li, C.; Allman, G. W.; Savage, P. B. J. Antimicrob. Chemother. 2001, 47, 671.

17. Guan, Q.; Schmidt, E. J.; Boswell, S. R.; Li, C.; Allman, G. W.; Savage, P. B. Org. Lett. 2000, 2, 2837.

18. Rehman, A.; Li. C.; Budge, L. P.; Street, S. E.; Savage, P. B. Tetrahedron Lett. 1999, 40, 1865.

19. Hazra, B. G.; Pore, V. S.; Dey, S. K.; Datta, S.; Darokar, M. P.; Saikia, D.; Khanuja, S. P. S.; Thakur, A. P. Bioorg. Med. Chem. Lett. 2004, 14, 773.

20. Moore, K. S.; Wehrli, S.; Roder, H.; Rogers, M.; Forrest, J. N.; McCrimmon, D.; Zasloff, M. Proc. Natl. Acad. Sci. 1993, 90, 1354.

21. Moriarty, R. M.; Tuladhar, S. M.; Guo, L.; Wehrli, S. Tetrahedron Lett. 1994, 35, 8103.

22. Deng, G; Dewa, T.; Regen, S. L. J. Am. Chem. Soc. 1996, 118, 8975.

23. Kukuchi, K.; Bernard, E. M.; Sadownik, A.; Regen, S. L.; Armstrong, D. Antimicrob. Agents Chemother. 1997, 41, 1433. 
24. Merritt, M.; Lanier, M.; Deng, G.; Regen, S. L. J. Am. Chem. Soc. 1998, 120, 8494.

25. Sadownik, A.; Deng, G; Janout, V.; Regen, S. L. J. Am. Chem. Soc. 1995, 117, 6138.

26. Otto, S.; Osifchin, M.; Regen, S. L. J. Am. Chem. Soc. 1999, 121, 7276.

27. Bandyopadhyay, P.; Janout, V.; Zhang, Lan-hui.; Sawko, J. A.; Regen, S. L. J. Am. Chem. Soc. 2000, 122, 12888.

28. Bandyopadhyay, P.; Bandyopadhyay, P.; Regen, S. L. J. Am. Chem. Soc. 2002, 124, 11254.

29. Zhang, J.; Jing, B.; Regen, S. L. J. Am. Chem. Soc. 2003, 125, 13984.

30. Maloy, W. L.; Kari, U. P. Biopolymers. 1995, 37, 105.

31. Beamer, L. J.; Carrol, S. F.; Eisenberg, D. Biochem. Pharm. 1999, 57, 225.

32. Savage, P. B. Eur. J. Org. Chem. 2002, 759.

33. Salunke, D. B.; Hazra, B. G.; Pore, V. S.; Bhat, M. K.; Nahar; P. B. Deshpande, M. V. J. Med. Chem. 2004, 47, 1591.

34. Vigushin, D. M.; Ali, S.; Dace, P. E.; Mirsaidi, N.; Ito, K.; Adcock, I.; Combes, R. C. Clinical Cancer Research 2001, 7, 971.

35. Clarke, B. THE LANCET oncology 2001, 2, 327. 